V Congresso Brasileiro de Informática na Educação (CBIE 2016)

Anais dos Workshops do V Congresso Brasileiro de Informática na Educação (CBIE 2016)

\title{
Jovem Detetive
}

Francisca Julianne P. Holanda ${ }^{1}$, Gabriel Rodrigues de Araujo ${ }^{1}$, Hiago Bruno Rabelo $^{1}$, Breno Sousa ${ }^{1}$, José Aires de Castro Filho ${ }^{1}$, Georgia da Cruz Pereira ${ }^{1}$

${ }^{1}$ Sistemas e Mídias Digitais - Instituto UFC Virtual, Universidade Federal do Ceará (UFC). Campus do Pici - Fortaleza - CE - Brasil.

\{julianneufc, gabrielaraujo9001, contato.hiagobruno\}egmail.com, breno bgslehotmail.com

Resumo. Este trabalho descreve o desenvolvimento do recurso Jovem Detetive, um jogo educacional de investigação. O jogo tem mecânica inspirada na franquia "Where in the world is Carmen Sandiego?", e seu design, no jogo Phoenix Wright. O projeto foi desenvolvido com o intuito de propagar a cultura latinoamericana, visando ao aprendizado da diversidade cultural. Utilizando-se da tecnologia Web, HTML5 e JavaScript, Jovem Detetive apresenta uma abordagem de conteúdos históricos, geográficos e culturais, visando desenvolver o raciocínio lógico e incentivando os alunos a aprenderem enquanto se divertem. $O$ público-alvo são alunos do Ensino Fundamental, com faixa etária entre 11 e 15 anos.

\section{Cenário de uso}

Fundamental no processo de aprendizagem, a cultura é um componente ativo na vida do ser humano e tem um papel de suma importância na formação de um indivíduo crítico. Na concepção de Vygotsky, é impossível pensar o ser humano privado do contato com um grupo cultural. Pois o grupo, além de lhe fornecer os instrumentos e signos necessários para desenvolver atividades psicológicas mediadas, desenvolve também o pensamento crítico ao lidar com a diversidade cultural.

Essas diferenças culturais podem trazer diversos problemas, principalmente nas escolas, como bullying ou esteriótipos, que em sua maioria são fruto da desinformação. Nesse contexto, o Colégio Sápiens, uma escola de Ensino Fundamental da rede particular de ensino de Fortaleza, notando a falta de visibilidade da cultura latinoamericana entre os jovens - que têm em primeiro plano as culturas norteamericana e européia - promoveu um evento sobre a cultura dos países da América Latina. Na ocasião, os alunos estudam a cultura de cada país e apresentam trabalhos a respeito no dia do evento.

Para o estudo não se limitar ao evento, foi sugerido o desenvolvimento de um recurso interativo para ser utilizado tanto como ferramenta para compreender melhor o que aprenderam, como para descobrir novas informações, de forma atraente e divertida. Vale ressaltar a importância da tecnologia na educação. Como assinala Castells (2007, p. 108), "todos os processos de nossa existência individual e coletiva são diretamente moldados pelo novo meio tecnológico.”. Tendo em vista a intensa relação de interdependência dos jovens com a tecnologia, é possível afirmar que o desenvolvimento cognitivo associado à ela atua mais fortemente neste grupo. Portanto, a utilização de recursos digitais, como jogos 
V Congresso Brasileiro de Informática na Educação (CBIE 2016)

Anais dos Workshops do V Congresso Brasileiro de Informática na Educação (CBIE 2016)

e aplicações interativas educacionais, tem papel fundamental para a consolidação da aprendizagem entre os jovens e, também, valorização cultural.

Com base nisso, desenvolvemos um jogo de investigação chamado Jovem Detetive, que tem como público-alvo os alunos pré-adolescentes e adolescentes entre 11 e 15 anos. Jovem Detetive traz a cultura de países como Brasil, Argentina, Chile, México e Venezuela. Além de abordar a cultura de cada país de forma geral, há informações históricas e geográficas nas pistas do jogo, e quando o jogador é apresentado ao país que chegou. Por ser um jogo investigativo, os alunos sentem-se estimulados a jogar mais vezes e completar mais missões. O recurso é, portanto, um instrumento mediador do conhecimento.

A próxima seção descreve o processo de desenvolvimento do Jovem Detetive.

\section{Desenvolvimento}

Jovem Detetive teve seu desenvolvimento iniciado no curso de Bacharelado em Sistemas e Mídias Digitais, da Universidade Federal do Ceará. Devia-se desenvolver um recurso interativo para um cliente real. Com base no Design Thinking, trabalhou-se o brainstorming e pesquisas com público-alvo. O projeto foi desenvolvido dentro do escopo de um conjunto de disciplinas do curso. Sendo assim, seu desenvolvido possuía restrições importantes quanto às tecnologias utilizadas. Em relação a isso, a disciplina de Programação II definiu que o aplicativo seria Web (HTML5) e desenvolvido utilizando a linguagem JavaScript.

À medida que o projeto prosseguia, a equipe documentava o andamento das atividades e entregava elementos do produto (proposta do recurso, narrativa, interface, personagens, etc) semanalmente. Estes elementos eram avaliados de modo a apontar melhorias, bem como elementos que ainda precisavam ser trabalhados.

A equipe optou pela utilização do Canvas para realizar a criação do jogo. Canvas é uma região da página Web em que podemos desenhar por meio de JavaScript. Disponível a partir do HTML5, essa tecnologia consegue lidar com textos, imagens, vídeos e aúdios.

Adicionalmente, utilizamos a biblioteca de JavaScript para Canvas: CreateJS, que encapsula e oferece diversos atalhos para operações como: desenhar uma imagem no Canvas; pré-carregar o conteúdo; responder a interações do usuário; fazer animações e transições, entre outros. Assim, todo o aplicativo foi desenvolvido com essa biblioteca ou, muitas vezes, com JavaScript puro.

\section{Apresentação do Software}

Para jogar Jovem Detetive, é necessário acessar o link (http://randomsmd.blogspot.com.br/2015/12/jovem-detetive-v12.html) e baixar o arquivo .ZIP para o computador. Após isso, deve-se extrair o projeto utilizando algum software de descompressão (WinRAR, por exemplo). Por fim, dentro da pasta extraída, clicar com o botão direito do mouse sobre o arquivo JovemDetetive.html e abri-lo em qualquer navegador disponível. Jovem Detetive foi criado para funcionar em desktop, portanto seu uso em dispositivos móveis não é garantido.

Jovem Detetive é um jogo de investigação criado em primeira pessoa, para que qualquer jogador possa se identificar como sendo o personagem principal de uma jornada. 
V Congresso Brasileiro de Informática na Educação (CBIE 2016)

Anais dos Workshops do V Congresso Brasileiro de Informática na Educação (CBIE 2016)

Por esse motivo, o personagem que aparece no menu principal possui uma silhueta pouco definida, que pode ser tanto um menino como uma menina.

No menu inicial, ao clicar em INVESTIGAR, aparecerá o Inspetor Canário - diretor da fictícia Organização de Investigação da América Latina. O Inspetor Canário explica, através de um tablet, que o desempenho do jogador na Academia de Jovens Detetives lhe chamou atenção e que agora está interessado em tê-lo como detetive profissional. Porém, para isso, o jogador terá de provar seu valor solucionando casos de roubos de relíquias pela América Latina.Quando a fala de Canário terminar, o jogador deverá aceitar a missão.

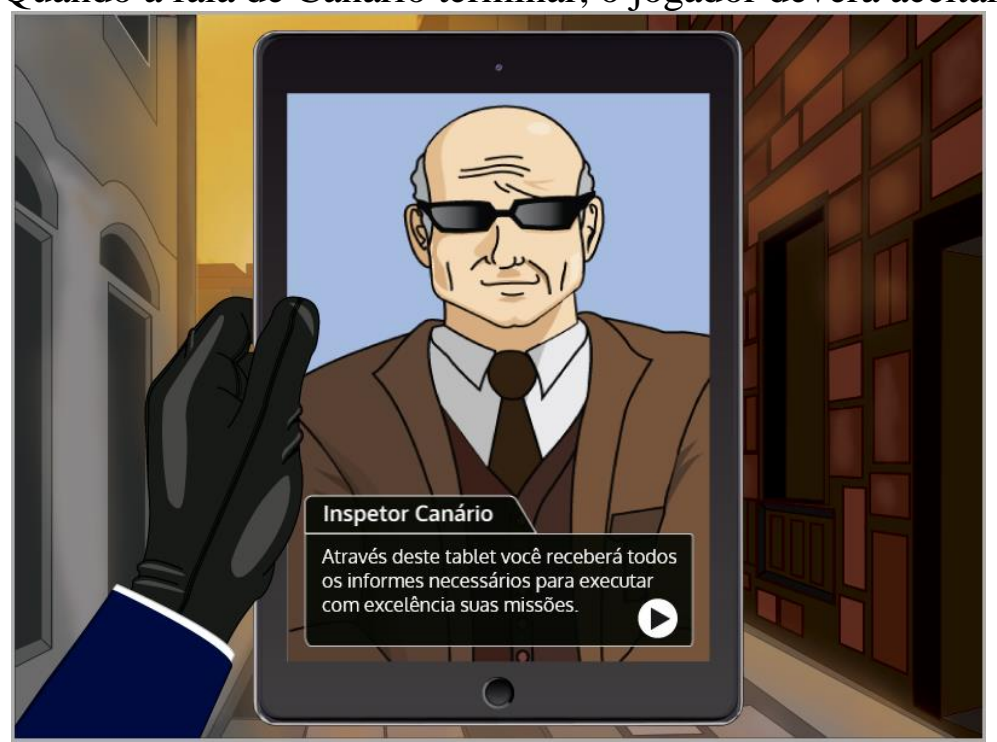

Figura 1 - Instruções do Inspetor Canário (elaborada pelos autores)

Surgirá a descrição de uma nova missão, que é escolhida aleatoriamente e sempre aponta para um monumento muito importante de algum país que foi roubado.

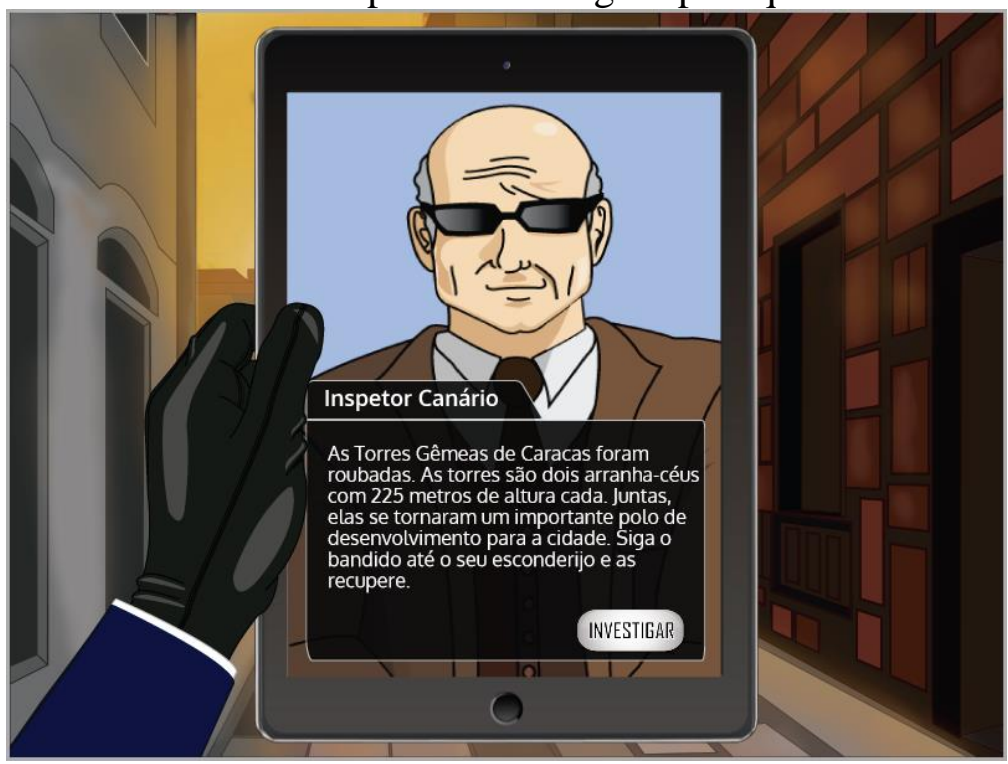

Figura 2 - Descrição da Missão (elaborada pelos autores) 
V Congresso Brasileiro de Informática na Educação (CBIE 2016)

Anais dos Workshops do V Congresso Brasileiro de Informática na Educação (CBIE 2016)

Ao iniciar uma missão, o jogador é levado até o aeroporto do país onde o roubo ocorreu. A partir daí, ele pode, por meio do menu "Lugares", transitar por dentro da cidade. O menu "Lugares" fará com que o tablet seja erguido, mostrando três opções, além do aeroporto, que o jogador pode escolher para viajar

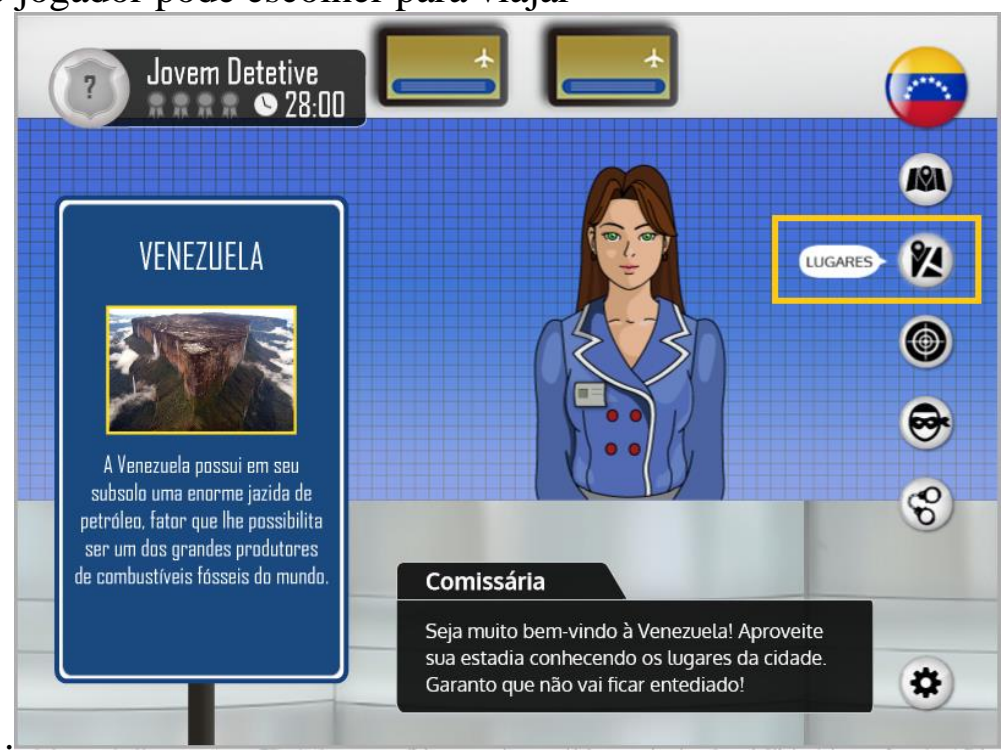

Figura 3 - Aeroporto, ponto de chegada dos países (elaborada pelos autores)

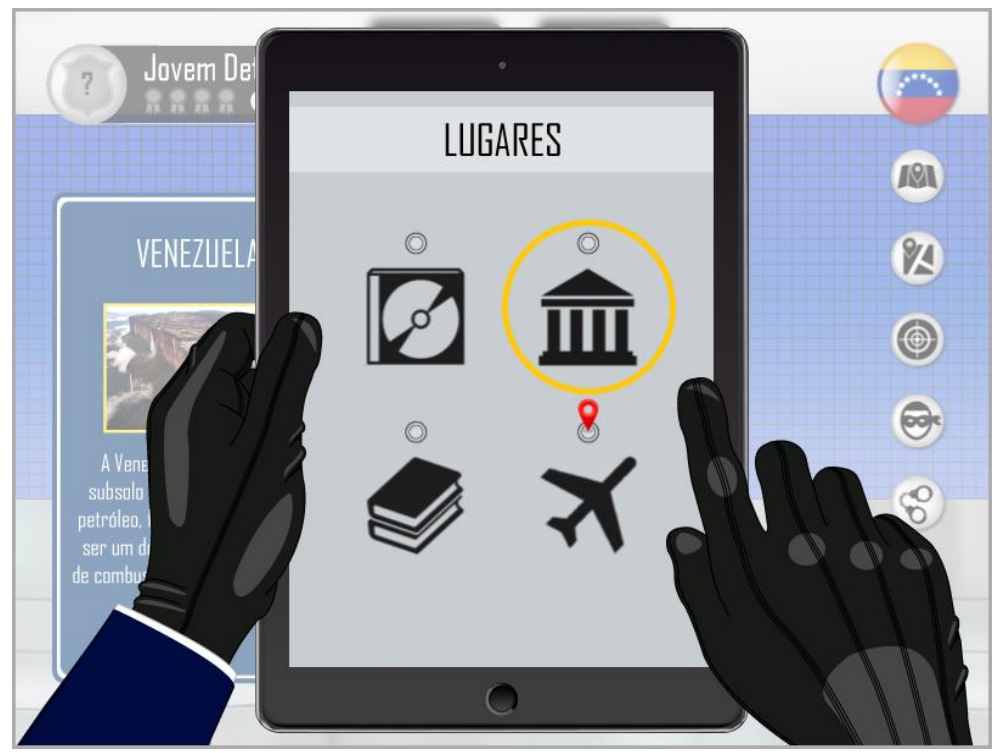

Figura 4- Menu "Lugares" de descolamento dentro da cidade (elaborada pelos autores)

Sempre que viajar para um local da cidade, o jogador se deparará com uma personagem, habitante daquele local, que lhe fornecerá duas pistas. A primeira pista se refere ao país para onde o ladrão fugiu. Já a segunda, refere-se a alguma característica física do bandido. Essa jogabilidade foi inspirada no famoso Where in the World is Carmen Sandiego? 
V Congresso Brasileiro de Informática na Educação (CBIE 2016)

Anais dos Workshops do V Congresso Brasileiro de Informática na Educação (CBIE 2016)

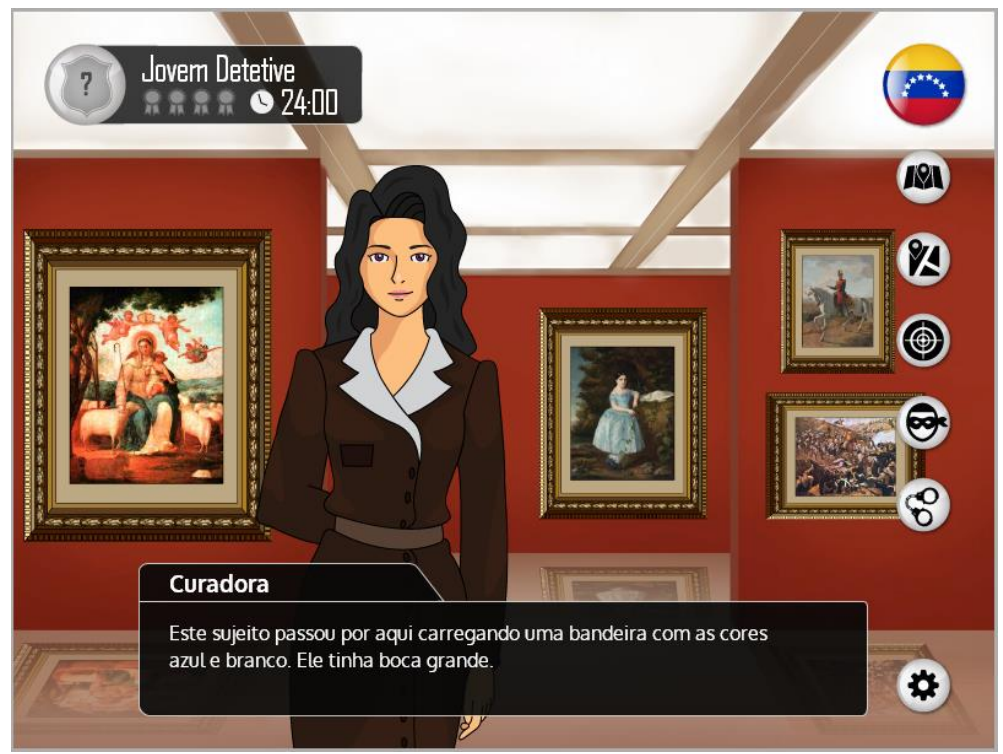

Figura 5- Museu, um dos lugares para receber pistas (elaborada pelos autores)

As pistas fornecidas pelas personagens sempre têm relação com o local em que o jogador está. Por exemplo, se ele estiver no museu, receberá pistas sobre cultura e arte; já se estiver no mercado, receberá pistas sobre culinária. A descrição da personagem acima indica que o ladrão fugiu para a Argentina (bandeira azul e branco).

A partir das dicas recebidas em relação às características físicas do ladrão, o jogador pode descobrir quem roubou o artefato. Para verificar a lista de suspeitos, deve-se acessar o menu "Suspeitos", que subirá o tablet com fotos e descrições de cada um dos suspeitos de cometer o crime. A descrição da personagem acima indica que o suspeito tem boca grande, portanto pode ser tanto Breno Silva como Gabriel Sanchéz.



Figura 6- Tela de suspeitos (elaborada pelos autores) 
V Congresso Brasileiro de Informática na Educação (CBIE 2016)

Anais dos Workshops do V Congresso Brasileiro de Informática na Educação (CBIE 2016)

Tendo descoberto a próxima localização do ladrão, o jogador pode viajar até o país acessando o "Mapa", que fica acima do menu "Lugares".

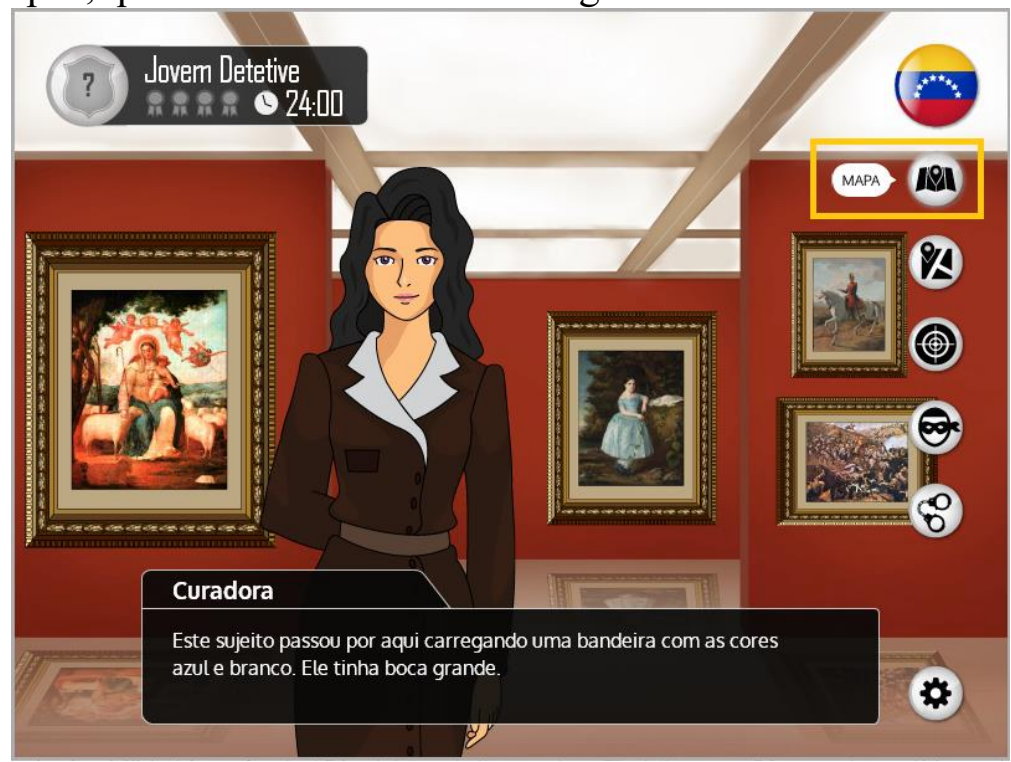

Figura 7- Museu, um dos lugares para receber pistas (elaborada pelos autores)

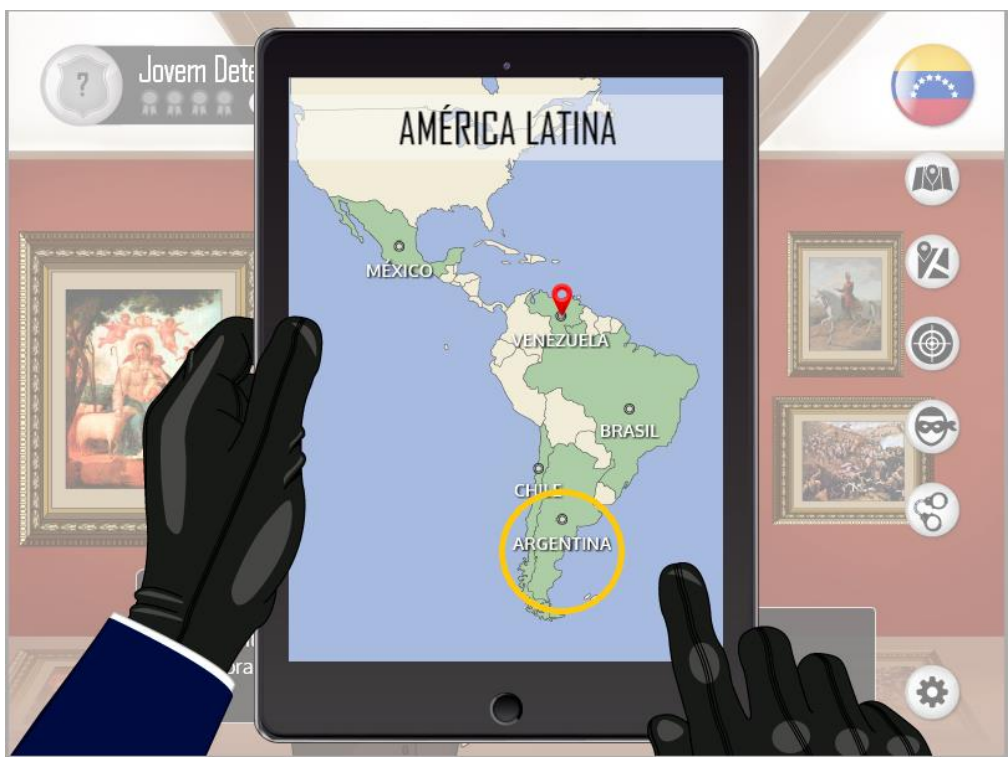

Figura 8- Menu "Mapa" de descolamento entre países (elaborada pelos autores)

O jogo prossegue de forma semelhante, com o jogador recebendo pistas e perseguindo o ladrão por entre os países da América Latina. Se ele conseguir chegar ao país definitivo antes de o tempo acabar, os personagens lhe dirão que "algo estranho está acontecendo na cidade". A partir de então, o jogador precisa decidir, com base nas dicas que recebeu, quem é o ladrão que cometeu o crime. Para isso, deve-se acessar o menu "Mandado" e selecionar o suspeito correto. 
V Congresso Brasileiro de Informática na Educação (CBIE 2016)

Anais dos Workshops do V Congresso Brasileiro de Informática na Educação (CBIE 2016)

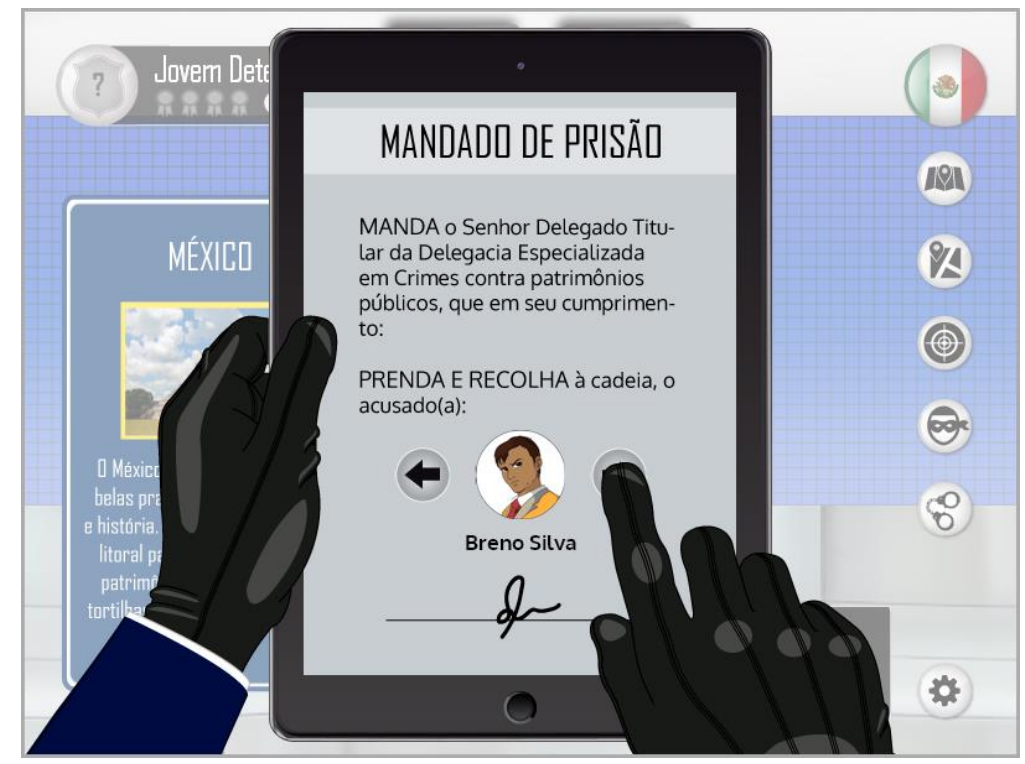

Figura 9- Mandado de prisão (elaborada pelos autores)

Gerar um mandado para o suspeito é importante, pois, sem ele, mesmo que o jogador chegue até o ladrão, este não poderá ser preso. Da mesma forma, se o mandado gerado estiver indicando o suspeito errado, o ladrão não poderá ser preso.

Escolhido o suspeito, o jogador deve vasculhar os lugares da cidade à sua procura. Ao encontrá-lo, se o mandado emitido estiver corretamente preenchido, o ladrão será preso e o jogador ganhará uma medalha. Se não, o ladrão escapará, mas o jogador ganhará uma nova oportunidade, com uma nova missão.

Um vídeo mostrando o gameplay do Jovem Detetive está disponível em: https://youtu.be/2WS8Yx2O8Ek.

\section{Considerações finais}

Conforme exposto neste artigo, temos a certeza do importante papel da cultura no aprendizado, permitindo a socialização e discussão sobre a diversidade cultural em sala de aula. Sabemos, também, que é dever da escola socializar o conhecimento. Nessa perspectiva, a tecnologia é uma grande aliada, trazendo os temas de forma interativa, atrativa e divertida para os jovens. O jogo Jovem Detetive cumpre este objetivo, auxiliando não só o ensino de diversas culturas, mas também sobre a história e geografia de cada lugar.

A concepção conceitual e visual do jogo levou em consideração conhecimentos dos campos do design e cognição, e acreditamos que as mecânicas propostas tornam o projeto atrativo para uma grande quantidade de pessoas e que as pesquisas que fizemos fornecem embasamento suficiente para direcionarmos, com efetividade, o recurso ao público-alvo.

O projeto Jovem Detetive foi testado com êxito e boa receptividade entre os alunos do colégio Sapiens. Este resultado nos motiva a continuar o desenvolvimento. Em breve, o jogo trará a cultura e história de mais países latinos. 
V Congresso Brasileiro de Informática na Educação (CBIE 2016)

Anais dos Workshops do V Congresso Brasileiro de Informática na Educação (CBIE 2016)

\section{Referências}

Regis, F. e Messias, J. (2012) "Comunicação, Tecnologia e cognição: rearticulando homem, mundo e pensamento”. In: Regis, F.; Ortiz, A.; Affonso, L. C. e Timponi, R. “Tecnologias de Comunicação e Cognição". Porto Alegre: Sulina, p. 23-51.

Ferreira, L. G. (2012) “Jovens, uso das tecnologias da informação e comunicação e desenvolvimento cognitivo na cibercultura”. In: In: Regis, F.; Ortiz, A.; Affonso, L. C. e Timponi, R. Tecnologias de Comunicação e Cognição. Porto Alegre: Sulina, p. 94-116.

Oliveira, M. K. (1998) “A mediação simbólica”. In: Oliveira, M. K. Vygotsky Aprendizado e Desenvolvimento: Um processo sócio-histórico. Editora Scipione, pp. 2540 .

OLIVEIRA, M. K. D. (1997) "Vygotsky: Aprendizado e desenvolvimento; um processo sócio-histórico". 4 Ed. São Paulo: Editora Scipione.

ALVAREZ M. L. O. “A questão da diversidade cultural no processo de integração latinoamericana: o grande desafio do Século XXI”, http://repositorio.unb.br/bitstream/10482/2801/1/artigo_AQuest\%C3\%A3oDaDiversidadeC ultural.pdf

CANDAU, V. M. F. (2012) "Diferenças Culturais, Interculturalidade e Educação em Direitos Humanos", http://www.scielo.br/pdf/es/v33n118/v33n118a15.pdf

PEREIRA, N. B. “A Importância de Trabalhar a Diversidade Cultural na Escola”, http://www.impactosmt.com.br/index.php/artigos/16-a-importancia-de-trabalhar-adiversidade-cultural-na-escola, 